\title{
Efeito da leucoaférese sobre o leucograma de equinos submetidos a modelo de sepse
}

Alvaro de Paula Lage de Oliveira[a]", Odael Spadeto Junior ${ }^{[a]}$, Cahue Francisco Rosa Paz ${ }^{[a]}$, Leticia Oliveira Cota ${ }^{[a]}$, Thairê Pereira Maróstica ${ }^{[a]}$, Rodrigo Martins Ribeiro ${ }^{[a]}$, Patrícia de Castro Duarte ${ }^{[a]}$, Pierre Barnabé Escodro ${ }^{[b]}$, Rafael Resende Faleiros ${ }^{[a]}$

[a] Universidade Federal de Minas Gerais (UFMG), Belo Horizonte, MG, Brasil

[b] Universidade Federal de Alagoas (UFAL), Viçosa, AL, Brasil

*Autor correspondente

e-mail: oliveira.medvet@hotmail.com

\section{Resumo}

A aférese é o procedimento caracterizado pela separação de uma parcela do sangue de um paciente, por meio de centrifugação ou filtração, retornando os demais hemocomponentes à corrente sanguínea. De acordo com o componente removido, a aférese pode ser classificada em plasmaférese (plasma), leucaférese (leucócitos), eritrocitaférese (eritrócitos) e plaquetaférese (plaquetas) (Pinto, 2013). 0 objetivo dessa pesquisa foi descrever a técnica e verificar os efeitos da leucoaférese por fluxo contínuo sobre as contagens de leucócitos sanguíneos em equinos submetidos a um modelo de síndrome da resposta inflamatória sistêmica (SIRS) pela administração gástrica de oligofrutose. Estudou-se a hipótese de que a leucoaférese de fluxo contínuo é um procedimento seguro e eficaz em reduzir a presença de células inflamatórias circulantes em equinos submetidos a um protocolo de SIRS. A metodologia experimental foi aprovada pelo Comitê de Ética Sobre Experimentação Animal da UFMG (CETEA/UFMG 281/2013). Foram utilizados seis equinos, fêmeas, sem raça definida, com idade média de 10,5 \pm 5 anos, pesando $381 \pm 11 \mathrm{~kg}$. Previamente ao procedimento de separação dos leucócitos, os animais formam submetidos a um protocolo de indução de sepse. Doze horas após a indução, os equinos foram contidos em tronco e ambas as jugulares foram canuladas com cateteres 14 G. Para a separação dos leucócitos, foi utilizada uma máquina com sistema de aférese Cobe Spectra (Terumo BCT, Lakewwod USA), com kit comercial Terumo BCT WBC por sistema de coleta por fluxo contínuo com duplo acesso venoso. A separação dos leucócitos foi feita por meio de centrifugação (765 RPM), com fator de separação 500, até serem processados uma média de 16.628,1 $\mathrm{ml}( \pm 1.300 \mathrm{ml})$ de sangue (a taxa de retirada foi de $75 \mathrm{ml}$ por minuto), durante quatro horas (M0 a M4). Ainda, para facilitar a separação de leucócitos, foi administrada, pela via de infusão, solução hidroxetilamido - HES ( \pm 966,67 ml). 0 volume de sangue processado foi em média $( \pm \mathrm{DP})$ de $16.628 \mathrm{ml}( \pm 275 \mathrm{ml})$, obtendo-se $682 \mathrm{ml}( \pm 40 \mathrm{ml})$ de plasma 
concentrado em leucócitos. 0 procedimento de leucoaférese se mostrou eficiente em reduzir as contagens de leucócitos totais circulantes já na primeira hora, com uma redução de 18,7\%. Nas contagens diferenciais, diferenças estatísticas foram detectadas apenas nos linfócitos, na comparação entre M0 e M2. Entretanto, reduções numéricas foram observadas em todos os tipos de leucócitos, como 31\% de neutrófilos, 59\% de linfócitos, 43,5\% de monócitos e a remoção completa de bastonetes. Em conclusão, confirma-se a hipótese de que a leucoaférese de fluxo contínuo é um procedimento seguro e eficaz em reduzir a presença de células inflamatórias circulantes em equinos submetidos a um protocolo de sepse.

Palavras-chave: Laminite. Tratamento. Leucócitos. 